\title{
ÉTICA DE MERCADO Y PRÁCTICA CONTRACTUAL JURÍDICO-PRIVADA DE LAS PARTICIPACIONES PREFERENTES
}

\author{
Autor: Javier Ibáñez Jiménez. ${ }^{1}$ \\ Coordinador del Grupo "Derecho, Mercado y Sociedad Global Sostenible" (Comillas). \\ Codirector de la Cátedra Garrigues de Derecho de Sociedades.
}

\section{Resumen}

Se trata de desentrañar en clave ética de mercado el régimen jurídico-privado y el de control administrativo español de las denominadas participaciones preferentes, especialmente desde la incidencia de los mecanismos de comercialización bancaria en red de sus emisiones sobre el nivel de desprotección jurídica del inversor bancario minorista o no profesional. En particular, se examina el caso de la comercialización a partir de 2008.

Palabras clave: Participaciones preferentes. Ética de mercados. Contratación privada.

\footnotetext{
1 jibanez@der.upcomillas.es
} 
Market Ethics and Private-Law Contractual Practice in Preferential Shares.

\begin{abstract}
Some key ethical aspects of the Spanish contractual private-law and administrative regime in force on the so called preferent participations are shown in this paper, particularly under the standpoint of the impact of banking network distribution mechanisms of their IPO issues on non-professional banking clients and investors, mainly since 2008.
\end{abstract}

Keywords: Preferred or Preferential shares. Private-law contracting. Market Ethics.

\title{
1. LAÉTICA DELMERCADOY LADISTRIBUCIÓNDE PREFERENTES.
}

Constituye el objeto del presente trabajo un análisis, desde una perspectiva dual ética y jurídica, de la situación generada en España por la emisión de participaciones preferentes como modalidad de valor negociable -de gran actualidad por haber sido profusamente emitida por entidades de crédito españolas en los últimos años, en plena crisis financiera y económica-, como parte de determinadas estrategias de financiamiento dirigidas al saneamiento y fortalecimiento de sus balances bancarios. Para la banca, la medida de emitir preferentes era de necesaria adopción ante la severa falta de liquidez y recursos propios que, pese a su negación sistemática por grupos parlamentarios, portavoces políticos y medios de comunicación, era una realidad que, como se ha demostrado posteriormente, afectaba de plano a la estructura de financiación de estas entidades. En concreto, algunas de las más importantes entidades de crédito se han fusionado o han sufrido procesos de saneamiento intervenido públicamente -rescate financiero o bail out-; las fusiones han sido el expediente reestructurador favorito, que ha afectado especialmente a Cajas de Ahorros, sin perjuicio de que muchas de ellas, y asimismo otras entidades bancarias han sido intervenidas en su administración por el Banco de España, llegando en ocasiones a cesar en el pago del rendimiento o intereses de tales participaciones; con causas que, a la postre, han determinado la pérdida de su liquidez y el consiguiente fracaso de la inversión que representan.

Se da la circunstancia añadida de que en los procesos de emisión, distribución y colocación de los llamados valores preferentes se cuentan por decenas de miles los afectados, lo que ha popularizado el impacto social del problema, hasta llegar 
a erigirse su solución en una prioridad muy alta para la dirección de los bancos y banqueros de inversión. Se da asimismo en paralelo la especial circunstancia en los últimos años de que una muy considerable parte del total del valor nominal de los fondos captados del público por las entidades de crédito mediante el mecanismo de la emisión de participaciones preferentes, procedía de depósitos a la vista o a plazo cuya titularidad correspondía a clientes calificables como minoristas con arreglo al art. 78 bis de la Ley 24/1988, del Mercado de Valores (en adelante LMV), así como que, para colocar tales participaciones preferentes, las entidades de crédito han recurrido a técnicas internas y directas, es decir, a través de sus oficinas mediante trato personal y directo con tal clase de clientes ${ }^{2}$.

Puede afirmarse desde el punto de vista ético y de la filosofía jurídica que, en la mayor parte de los supuestos, la emisión de participaciones preferentes por entidades de crédito ha constituido una operación de dudosa transparencia y asimismo de frágil integridad, cuando menos desde el punto de vista de la óptica específica de la ética del mercado de capitales ${ }^{3}$. En efecto, se vislumbran en su configuración y estructura distributiva rasgos en cierta medida abusivos en cuanto que la contratación ha provenido por lo general de la iniciativa bancaria, y además ha sido dirigida de forma sistemática a transformar en neto patrimonial el pasivo representado por el dinero que los suscriptores de aquéllas mantenían en régimen de contratos de depósito bancario.

El tratamiento jurídico y contable que merece dispensarse por el banco al ahorro popular captado mediante participaciones preferentes, una vez aceptada por los inversores la oferta de adquisición de preferentes, es, según la regulación especial de éstas, el propio del patrimonio neto -art. 36.1.c) de nuestro Código de Comercio-. En efecto el dinero «traspasado» hacia ellas desde depósitos a plazo o a la vista cesa como deuda del emisor -pasivo, en términos contables- para pasar a formar parte ministerio legis del neto patrimonial de éste, de suerte que los titulares de los valores adquiridos a cambio de los fondos captados pasan a ser partícipes de su riesgo patrimonial de socio, esto es, de su riesgo societario básico. Este es un hecho que sin duda ha pasado inadvertido en la práctica a la mayoría de los clientes, dada la diversidad de personas a quienes se comercializa el producto y su popularización, extendiéndose no solo a minoristas habituados a la banca de inversión, sino sobre todo a un grueso de personas absolutamente ajenas a otra operatoria que no sea la tradicional o típica de la banca comercial.

${ }^{2}$ Cf. Alonso Espinosa, F. , "Participaciones preferentes y clientes minoristas de entidades de crédito, 7875 Diario la Ley, Sección Doctrina, XXIII, 7.06.2012.

3 Cf. Fernández-Armesto, J., "La ética en los mercados de valores, problema crucial de las sociedades y sistemas capitalistas contemporáneos”, en Ibáñez, J. y Fernández, J. L. -dirs.-, Ética y mercado de valores, Marcial Pons, Madrid, 2002, pp. 17-24; Ibáñez, J., "Ética y normas de conducta profesional en el mercado de valores", en Ética y mercado de valores, cit., pp. 35-37 y pp. 44-49; Ruiz Martínez, R. e Ibáñez, J., "El inversor como víctima de la publicidad financiera", en Ética, cit., pp. 95-102. 
Pueden someramente enunciarse como concausas fundamentales y fundantes del éxito de la colocación de preferentes en operaciones masivas de comercialización, además de la clase de valor negociable seleccionado por la administración de las entidades emisoras -capaz de convertir pasivo en patrimonio neto prácticamente arte magica-, los siguientes: (i) La técnica combinada de publicitación comercial y colocación o régimen de oferta de los valores que en la comercialización de preferentes ha sido en su mayor parte directa y personal hacia los clientes minoristas de la entidad de crédito, a iniciativa de ésta y mediante empleo de su personal y oficinas o redes locales; y (ii) la referida condición o estatuto legal de los destinatarios de la oferta de preferentes, en medida abrumadoramente predominante, clientes minoristas (cfr. art. 78 bis LMV); los suscriptores, en general, mantenían una relación de confianza con el personal de la entidad de crédito emisora, confianza quebrada a posteriori en no pocos casos, al menos en aquellos en que haya sido sorprendida la buena fe de tales clientes al quedar transformados en financiadores de riesgo, quizá, sin pretenderlo, y aun sin advertirlo hasta que se consumaron las pérdidas procedentes de la inversión ${ }^{4}$.

${ }^{4}$ Así, a un cliente octogenario, que lo era desde 1952, un director de su sucursal de La Caixa le llamó en 2009 para ofrecerle preferentes "por ser un buen cliente"; le explicó que podría recuperar su dinero (192.000 euros, los ahorros de su vida) en 48 horas dando orden de vender; pero en 2012 le ofrecen un canje de sus participaciones por derechos de crédito (obligaciones a 10 años). Comoquiera que las normas prudenciales internacionales sobre capital y solvencia bancaria del Banco Internacional de Pagos, en su tercera versión (conocida por Basilea III) excluye a las preferentes del cómputo de los recursos propios de los bancos, estos se apresuraron a canjearlos a clientes por bonos o acciones, lo que algunos, como Santander, BBVA o Sabadell, consiguieron sin demasiado revuelo, respetando en esencia la equivalencia del capital invertido por los clientes. Pero en el caso de La Caixa, solo el 30\% se ha ofrecía en 2011 e inicios de 2012 en dinero o en valores de la entidad; el $70 \%$ es deuda a 10 años, vencimiento que en teoría mejora la posición inversora (en principio perpetua, como la de un socio), pero que en la práctica reduce drásticamente la liquidez considerando que inicialmente el banco ofrecía una ventana de liquidez cada 48 horas, plazo similar al de un mercado secundario oficial. He aquí otra trampa oculta del producto: la pérdida de liquidez en caso de dificultades del emisor. Para evitar agravamiento de los daños infligidos a su reputación corporativa, La Caixa comenzó a ofrecer en el segundo semestre de 2012 canjes en acciones o en depósitos, que, aunque de menor rentabilidad esperada, ofrecían liquidez y seguridad de reembolso. Pero en el caso de Bankia (más de 3000 millones colocados), la propia Comisión Europea vetó el depósito del $80 \%$ del nominal a 4 años y $5 \%$ de interés ofrecido por la entidad, que competía deslealmente con el resto del mercado al financiarse con dinero público. En primera instancia, los bancos suelen recurrir indiscriminadamente las sentencias desfavorables, especialmente cuando el fundamento petitorio que invocan los letrados de los clientes se sustancia en un déficit informativo sobre los riesgos. Incluso recurren en supuestos como el del juez de Mataró que anuló en octubre de 2012 una venta de 30.000 euros de preferentes a una familia con hijos afectados por síndrome de Down (quienes, incluso firmaron el contrato); aunque el sentimiento moral entre la ciudadanía se identifica con el del Colectivo Ronda, una cooperativa de abogados que asesora a cientos de afectados según el cual esas políticas bancarias de recurrir cualquier sentencia alargan "innecesariamente los procesos judiciales y el sufrimiento de las personas afectadas", lo cierto es que la incertidumbre sobre el resultado de la litis y, sobre todo, la liquidez retenida por los bancos perdedores ínterin se ejecutan las sentencias, son factores que aún inclinan a los gestores hacia el cortoplacismo autocomplaciente, pese al deterioro reputacional evidente, quizá irreversible, que entrañan esas políticas. Acaso estén sus gestores firmemente convencidos de que la ética bancaria es inexistente, y que toda relación bancaria se basa, por ambas partes, exclusivamente en la rentabilidad. El problema subyacente es que cualquier fábrica de capital se termina: las relaciones bancarias son, además de económicas, fiduciarias, intuitu personae; y, perdida la confianza, el negocio toca a su fin. 
No parece acertado pensar que ahorradores conservadores que jamás habían realizado movimientos en el mercado de capitales, o que los habían realizado en circunstancias extraordinarias o de forma esporádica, y que por tanto vienen caracterizados desde la óptica de su perfil inversor por su aversión al riesgo, se hallen en condiciones de entender al aceptar la oferta que les propone el banco el alcance esencial que comporta la transformación o transmutación de la posición jurídica que ocupan, pasando antes de aceptar la oferta de estar en el mercado crediticio como depositantes de dinero -situación jurídico-financiera de mínimo riesgo- para ocupar ex post la de inversores de riesgo máximo, incluso asumiendo en la mayor parte de los supuestos una posición de mayor nivel de riesgo de crédito que la propia de los accionistas o, en su caso, cuota-partícipes, de la entidad de crédito emisora. Tampoco cabe afirmar que el cumplimiento por la entidad de crédito emisora de las obligaciones de aprobación y registro por la CNMV de la información reglada relativa a tales emisiones (1) y el asentimiento tácito o expreso a tal estrategia por parte de poderes públicos directamente competentes en tal ámbito, como es el Banco de España, sirvan para convalidarla plenamente.

Procede, así, realizar las consideraciones que siguen, dirigidas a mostrar el nivel de incompatibilidad entre las colocaciones masivas de participaciones preferentes entre la clientela minorista de las entidades de crédito, y unas adecuadas prácticas bancarias.

\section{AMBIGÜEDAD DEL TÉRMINO PREFERENCIA Y SU PRESENTACIÓN COMERCIAL POR LA BANCA ANTE SU CLIENTELA COMO CUALIDAD JURÍDICA POSITIVA DE LAS PREFERENTES.}

La disciplina de la participación preferente como valor negociable singular emitido por entidades de crédito del sistema financiero español se contenía ya en una disposición adicional, la segunda de la Ley 13/1985, de 25 de mayo, de Coeficientes de Inversión, Recursos Propios y Obligaciones de Información de los Intermediarios Financieros, introducida en ésta hace una década por la Ley 19/2003, de 4 de julio, que a su vez, al socaire de la crisis, fue modificada por el art. 1.10 de la Ley 6/2011, de 11 de abril (BOE de 12 de abril), que transpone a nuestro Derecho la Directiva 2009/111/CE, del Parlamento Europeo y del Consejo, de 16 de septiembre de 2009, en función, especialmente, de determinar las condiciones para admitir como recursos propios de las entidades de crédito a los que denomina instrumentos de capital híbridos, entre los que se incluye la participación preferente. El Decreto Ley 24/2012, de 31 de agosto, sobre reestructuración y resolución de entidades de crédito, viene a plasmar el consenso europeo fraguado en el Memorandum of Understanding de 20.07.2012 sobre esta materia, que se sustanciaba en aprobar normas que garantizasen al inversor "los ejercicios de responsabilidad subordinada" (apartado 18 del Memorandum), de modo que su 


\section{JAVIER IBÁÑEZ JiMÉNEZ}

inversión no llegue a devenir papel mojado, tanto si es titular de valores de deuda postergada o subordinada concursalmente, como si es titular de "instrumentos de capital híbrido", esto es, mixtos o a medio camino entre la renta fija (fondos ajenos de deuda del emisor) y la variable (fondos propios representativos del capital).

En efecto, la participación preferente es un valor negociable híbrido o mixto, de imprecisa naturaleza. Superficialmente parece responder a un valor de deuda por lo que, de partida, encajaría en la naturaleza propia de las obligaciones ex arts. 401 y ss. LSC (y Ley 211/1964), ya que éstas se caracterizan porque «reconocen o crean una deuda» contra su emisor; además, su regulación legal las ha calificado históricamente como «instrumentos de deuda». Sin embargo, atendido su régimen legal actual y su tratamiento contable, resulta que la participación preferente, pese a su carácter híbrido o mixto (usado en no pocas ocasiones para confundir al inversor o cliente) se halla mucho más próxima a las acciones y demás valores participativos que a las obligaciones y demás valores de deuda.

Debe llegado este punto afirmarse que designar o denominar legalmente «participación preferente» al valor negociable caracterizado por los aspectos expuestos anteriormente constituye un ejemplo de confusión legislativa, porque es una denominación equívoca, potencialmente engañosa o inductora a confusión precisamente en el caso de una inadecuada, negligente o torticera comercialización o distribución. Y ello es así en esencia debido a dos razones: (i) Porque en puridad no es una «participación» en sentido societario; y (ii) porque no incorpora ningún derecho que, en rigor, pueda calificarse como «preferente» desde la óptica de la atribución y ejercicio de derechos del adquirente. Desglosaremos ambas afirmaciones.

\subsection{La participación preferente no es una genuina «participación» en sentido societario.}

La participación preferente no es una participación en sentido societario relativo a la naturaleza y efectos de los contratos de participación social (1665 CC, 116 y 119 C Com), que es lo que con mayor fuerza sugiere en primer término la expresión jurídica «participación». La participación preferente no atribuye a su titular prima facie los derechos típicos del socio de la entidad emisora; por contra, sí se derivan de su titularidad obligaciones conexas o próximas, si no iguales, a las de orden propiamente societario contraídas por un socio, desde el prisma financiero o de participación en las pérdidas o riesgo patrimonial del emisor. El único «derecho» cierto o seguro de participación que la participación preferente incorpora en su acervo negocial interno, como título-valor o como derecho-valor anotado en cuenta, en caso de decantación, habitual hoy, por este sistema representativo de los derechos incorporados, el de participación en los resultados del emisor, y en un contexto de crisis, de facto, el de compartir o participar en la comunidad pérdidas del emisor sumergido en procesos de refinanciación, reestructuración o salvamento. 


\subsection{En la mayor parte de las emisiones habidas en los mercados españoles, la participación preferente no atribuye ningún derecho calificable como «preferente».}

La segunda razón de distanciamiento respecto a los clásicos valores de renta variable reside, así, en que la participación preferente tiene en realidad poco o nada de preferencial. No atribuye a su titular ningún derecho de retorno o reembolso del principal invertido preferente o privilegiado, sino, más bien, al contrario, confiere una posición jurídica postergada o ancilar análoga a la de los títulos de deuda concursalmente subordinados. La participación preferente no incorpora en la mayoría de las emisiones derecho de crédito alguno que ejercitar frente al emisor respecto al pago de su valor nominal. El nacimiento del tal derecho, teóricamente configurado en los folletos informativos de las emisiones, requiere sin embargo la concurrencia de tres presupuestos que, de facto, son de imposible o excepcional confluencia:

a) Que tuviese lugar la liquidación patrimonial de la entidad de crédito, por causa concursal o por otros supuestos de extinción de la persona jurídica emisora.

b) Que en el seno de la misma hubiese patrimonio suficiente para pagar la totalidad de los créditos contra ésta -incluso de los subordinados- de cualquier clase y rango que sean, así como para pagar todos los créditos contra la sociedad dominante del grupo o subgrupo consolidable al que pertenezca la entidad de crédito emisora de las participaciones preferentes.

c) Que, una vez realizados tales pagos, el patrimonio remanente de la entidad de crédito liquidada fuese suficiente para atender el nominal representado por las participaciones preferentes.

El nacimiento del derecho al pago del nominal de las participaciones preferentes exige, pues, una situación de suficiente solvencia de la entidad de crédito deudora tras su liquidación de la que resulte: (i) El pago de la totalidad de sus acreedores privilegiados y ordinarios; (ii) el pago de los créditos contra las sociedades que formen parte de su grupo o subgrupo consolidable; y (iii) que, tras ello, quede patrimonio remanente suficiente para atender el nominal representado por participaciones preferentes. Requisitos cuya producción es realmente muy improbable, cuando no imposible. Por tanto, la supuesta «preferencia» de la participación preferente es, además de una paradoja conceptual desde la óptica del derecho, una ambigüedad terminológica del legislador bien calculada por la banca para su empleo como reclamo en la distribución del producto. 


\section{JAVIER IBÁŃEZ JiMÉNEZ}

El término preferente se revela, así, engañoso, especialmente cuando la colocación del producto se diseña para ser distribuido entre la clientela minorista, pues el valor viene dotado de un contenido jurídico contrario a lo que sugiere su semántica. La pretendida «preferencia» del pseudocrédito incorporado al reembolso del valor invertido en la participación preferente, en el improbable caso de que llegare a nacer, solo tiene lugar ante los accionistas o asimilados (cuota-partícipes de cajas de ahorros, aportaciones de socios cooperativos) de la entidad de crédito emisora y tras la liquidación de ésta. No parece admisible desde la óptica de la ética del mercado, que es la ética de la transparencia y de la integridad, normativa y de los operadores, en aras de la eficiencia y recta asignación informada de recursos, que la propia Ley califique como preferente a tal tratamiento jurídico de la inversión en valores negociables. Tal preferencia no solo es inexistente inicialmente, sino que el derecho al pago del nominal de la participación preferente, en el difícil supuesto de que llegase a nacer, lo sería con carácter ultrasubordinado. La correcta aplicación al supuesto del principio de protección del inversor como informador del régimen de la inversión en valores negociables exige abolir esta denominación legal.

Por lo demás, la aplicación del principio de transparencia informativa que ha de regir las relaciones entre emisores de valores e inversores en los mismos exige designar a la «participación preferente» como lo que realmente es la de una acción de clase especial, desprovista de derechos políticos, que confiere derecho de percibir un dividendo máximo y mínimo condicionado a la generación en el periodo considerado de beneficios o reservas repartibles, en el balance del emisor o en el de su grupo de empresas; o, en su caso, a la decisión del órgano de administración de aquél, y con derecho preferente a obtener la cuota de patrimonio correspondiente a la inversión realizada en supuestos legales de liquidación.

Puede afirmarse que aplicar tal denominación o similar a la referida excluiría la validez de su colocación entre clientes minoristas si se atiende a las obligaciones de toda empresa de servicios de inversión respecto a la prestación de servicios sobre valores de los llamados complejos o de difícil comprensión de contenido por no avezados. En todo caso, la protección debida a los inversores minoristas exige renunciar a la inapropiada denominación legal con que se vinieron comercializando estos productos desde 2008 para aplicar otra más fundada en el referido principio de transparencia y, por tanto, más ajustada o sugerente de la posición jurídica real que tales valores incorporan. Así lo exigen los criterios normativos comunitarios recientes y el nuevo régimen nacional de comercialización de productos híbridos ${ }^{5}$, donde la transparencia informativa preside una regulación di-

${ }^{5}$ La exposición de motivos del RDL 24/2012, sub IV, afirma la necesidad de imponer una tutela del inversor, dando "respuestas decididas en relación con la comercialización de los instrumentos híbridos y otros productos complejos para el cliente minorista, entre los que se incluyen las participaciones preferentes, con el fin de evitar que se reproduzcan prácticas irregulares ocurridas durante los últimos años". 
rectamente encaminada a recuperar la correlación entre eficiencia, transparencia e integridad del mercado ${ }^{6}$.

\section{INDAGACIÓN SOBRE LA AUTÉNTICA NATURALEZA DE LAS "PREFERENTES".}

\subsection{Naturaleza como valor negociable y examen comparado de los instrumentos financieros preferentes.}

Los títulos-valor que conceden una preferencia o un privilegio al tenedor -inversor, si se trata de instrumentos negociables en mercados- pueden ser configurados por el deudor emisor con unas características muy variadas desde el punto de vista del contenido de las preferencias o privilegios otorgados ${ }^{7}$. En todos los casos, se incentiva la adquisición o suscripción justamente por medio de la preferencia, en unos casos orientada a privilegiar la posición jurídica del tenedor, y en otros sencillamente a compensarle por la pérdida de ciertos derechos asociados a títulos ordinarios o comunes de análogas características jurídicas y económicas. En otras ocasiones, en fin, lo que se persigue es -y ahí reside el riesgo para el adquirente- es atraer la inversión cuando las condiciones de mercado son difíciles o la situación interna del emisor de elevado riesgo, sin que necesariamente el hecho de conceder preferencias o ventajas frente a otros tenedores se interprete como un incremento significativo del riesgo. A todas las situaciones expuestas, en condiciones de eficiencia en los mercados, debe darse un equilibrio entre el riesgo asumido y la rentabilidad percibida por el tenedor; de lo contrario se producirá un perjuicio para una de las partes, por lo general el inversor desinformado sobre el desequilibrio que entraña el contrato.

Por lo común y en el ámbito angloamericano se emplea la expresión preferred stock (shares), o preferential share capital para referirse al caso de los valores de participación social de carácter preferente, y en particular a las acciones o partes alícuotas del capital de las sociedades anónimas que son preferentes; las cuales, sin embargo, son semejantes a la renta fija por su seguridad de cobro en el dividendo preferente, incluso en situación de pre-insolvencia.

En el derecho comparado, los valores preferentes o preferenciales (preferred ownership interest securities), por las razones económicas apuntadas, suelen configurarse en su régimen jurídico como valores cuya titularidad comporta renunciar a derechos políticos a cambio de otros económicos. Como ejemplo sirvan los derechos de voto, a los que renuncia el inversor en supuestos como el de las ac-

\footnotetext{
${ }^{6}$ Así lo hemos defendido en (2005), Usos y abusos en el mercado de capitales: conflictos éticos y economía regulatoria, tesis, Dpto. de Filosofía, Humanidades y Comunicación, UPCO, 25-39.

7 Sobre esta perspectiva es obligada la lectura de Fernández del Pozo, L.. Las participaciones preferentes: un híbrido financiero supletorio al capital social, Editorial Civitas / Thomson Reuters, Madrid, 1995,. Cap. primero.
} 


\section{JAVIER IBÁŃEZ JiMÉNEZ}

ciones sin voto -reguladas en nuestra Ley de Sociedades de Capital pero escasamente empleadas por emisores- a cambio de anteponerse a las acciones comunes $\mathrm{u}$ ordinarias tanto para cobrar el dividendo ordinario como para ser reembolsadas con preferencia en caso de liquidación.

Por otra parte, los valores preferentes suelen revestir carácter híbrido o mixto, situándose como se ha advertido en algún punto intermedio, por la configuración de su régimen, entre la propia de los valores de renta fija y los de renta variable, y de ahí la frecuencia con que introducen los emisores cláusulas de conversión o convertibilidad. Así, es frecuente en Estados Unidos la emisión de títulos preferentes convertibles en acciones ordinarias, característica que les dota de mayor seguridad en caso de insolvencia o concurso de acreedores. Y algunos, también con la idea de flexibilizar su régimen y reforzar así su carácter versátil, multivalente e híbrido, atento a necesidades de financiación especiales de los emisores, se dice que están estructurados, en el sentido de que su rentabilidad está referida a la que alcance otro activo, que opera como subyacente a un derivado, con la multiplicación de riesgos que esto comporta, similar a la que acontece en los fenómenos de cesión en cadena de créditos con emisiones respaldadas por los créditos transferidos, o titulización ${ }^{8}$.

Es nota común a todos los valores preferentes el pago previo en caso de insolvencia antes que a los comunes, pero después que a los acreedores (subordinación concursal, en el caso español). El caso de las preferentes emitidas y reguladas en España es de valores preferenciales o de preferencia de los denominados internacionalmente "perpetuos" (perpetual preferential or preferred shares), por no haber fecha fija de reembolso al accionista, aunque, como problema general, se plantea el del control del sistema de rescate, siempre en manos de los gestores de la compañía.

Pero no en todas las jurisdicciones los valores preferenciales generan una problemática semejante. La potencialidad para generar y diseminar elevadas pérdidas, y la consiguiente litigiosidad y riesgo reputacional para los emisores

\footnotetext{
${ }^{8}$ Recientemente, el Banco de Pagos Internacionales (BIS) eleva a rango de "criterio esencial" regulatorio el principio de que cada supervisor puede y debe imponer requisitos más severos o adicionales de capital si una entidad genera riesgos no adecuadamente cubiertos o cedidos mediante contratos celebrados por el banco, lo que precisamente sucede en el caso de la titulización, como en el de la estructuración (Comité de Supervisión de Basilea, Principios básicos para una supervisión bancaria eficaz, septiembre 2012, p. 48, accesible permanentemente en www. bis.org.; cf. Partal Ureña, A. e Ibáñez Jiménez, J.W. (2012), "Desencadenantes de la crisis financiera: la financiación estructurada", 13 Revista Electrónica de Pensamiento, Economía y Sociedad (REPES), 81-76; Banco de Pagos Internacionales(2008): $78^{\circ}$ informe Anual (1 de abril de 2007-31 de marzo de 2008), Basilea, passim; Catarineu, E. y Pérez, D. (2008): "La titulización de activos por parte de las entidades de crédito: El modelo español en el contexto internacional y su tratamiento desde el punto de vista de la regulación prudencial", Estabilidad Financiera, 14, 87-121; Dodd, R. (2007): "Los tentáculos de la crisis hipotecaria", Finanzas $\mathcal{E}$ desarrollo, diciembre, 15-19.Fender, I. y Mitchel, J. (2005): "Structured finance: complexity, risk and the use of rating", Bank of International Settlements Quarterly Review, junio, 67-79.
} 
dependen de dos factores básicos; una regulación eficiente y, sobre todo, su uso razonable por los emisores conforme a las circunstancias generales del mercado y las características de los destinatarios de la oferta, cuando son objeto de oferta pública.

En el caso de Alemania ${ }^{9}$, como en el de Chequia $^{10}$, se pueden emitir acciones preferentes por valor equivalente a un máximo del valor correspondiente al nominal de la mitad del capital total, regla que recuerda la de nuestra LSC (y anteriores arts. 91 y concordantes LSA) sobre valor máximo para la emisión de acciones sin voto. Las acciones preferenciales o preferentes alemanas son en general convertibles en acciones ordinarias, pero la conversión necesita aprobación por mayoría de votos en reunión de los accionistas. Esta garantía es ajena al régimen jurídico de nuestras preferentes, y es esencial para tutelar la posición del inversor minorista, pues si la votación en el caso anterior permite la aprobación en junta de la conversión, la ley alemana exige consenso con titulares de acciones preferenciales a convertir sus acciones, que suele ofrecer una prima equitativa a los titulares de acciones preferentes. La firme intención de hacerlo puede surgir de su política de rango de finanzas es decir en un índice específico.

En Canadá son frecuentes la emisiones de preferentes a partir de 2005, pero las garantías en la comercialización son muy superiores, en la medida en que, por un lado, el emisor que las distribuye, si son valores no reembolsables o perpetuos, debe contar con un capital de nivel 1 en los términos del Banco de Pagos Internacionales, por un lado, y por otro, las acciones suelen ser emitidas por especialistas en la emisión de acciones "compartidas" -split share corporations-, dan altos dividendos y cuentan con una fiscalidad favorable que las hace preferibles a la renta fija ordinaria; como en Sudáfrica, donde rige la exención por dividendos percibidos procedentes de preferred stock. En el caso español, contrariamente, las Cajas han emitido masivamente en 2009 con desconocimiento del cliente sobre la alta probabilidad de rescate bancario e imposibilidad de recuperar la inversión, cuando no con absoluta ignorancia de que el "híbrido" contratado es más un valor de participación social que de renta fija, pero solo al efecto de compartir la funesta suerte de las entidades desequilibradas financieramente, que precisamente veían en las preferentes un mecanismo alternativo de salvamento. En ningún

9 Vide schwarz, G. C., Europäisches Gesellschaftsrecht-ein Handbuch fuer Wissenschaft und Praxis, Baden Baden 2000, pp. 43 y 44; se confronta el modelo alemán con otros comparados, a propósito de un análisis de la regla one-share one-vote y su eventual función distorsionante de un óptimo gobierno corporativo, cuestión tratada en las sucesivas reformas comunitarias sobre la modificación del régimen de derechos de los accionistas minoritarios, y en particular la Directiva 2007/26/CE, transpuesta en España por Ley 25/2011, de 1 de agosto.

${ }^{10}$ Cf. Drevinek, K. / Severa, P., "Getting the Deal Through: Czech Republic”, 2005, sub 3, "Rights and Equitable Treatment of Shareholders, en Weil News Publications, recuperado en marzo de 2014 http:// www.weil.com/news/pubdetail.aspx?pub=3648. 
caso la rentabilidad, solo algo superior a la ofrecida en otros productos de renta fija, podía compensar el enorme riesgo asumido, a diferencia de como sucede en las emisiones canadienses o estadounidenses de productos parecidos ${ }^{11}$.

\subsection{Análisis particular de las emisiones españolas de preferentes.}

En el caso de las preferentes emitidas en los mercados españoles, la función financiera legalmente impuesta a la participación preferente muestra con claridad que no se trata de un valor de deuda o de captación de recursos financieros ajenos sujetos a restitución a unas condiciones de vencimiento; asimismo, su contenido legal revela que los derechos típicos que los valores de deuda atribuyen a sus titulares son en ella inexistentes y que la participación preferente es, realmente, una clase especial de acción legalmente regulada. En efecto, la función financiera legal de la participación preferente es la misma que la del capital social y demás elementos componentes del patrimonio neto: computar como recursos propios de la entidad de crédito emisora, lo que comporta un tratamiento jurídico y contable que la alejan, como hemos advertido, del propio de los valores de deuda. Debe tenerse presente en todo momento que los fondos invertidos en participaciones preferentes vienen sujetos ministerio legis y de forma permanente a la cobertura de las pérdidas del emisor, lo que acarrea el riesgo de la pérdida total de la inversión. Por ello, la función financiera legal de la participación preferente es de todo punto incompatible con la desempeñada por las obligaciones y demás valores de deuda, en la medida que éstos incorporan una deuda jurídicamente real del emisor y de ahí que se les dispense el tratamiento contable de los recursos ajenos ordinarios, sujetos a restitución o pasivo -cfr. art. 36.1.b) CCom- por virtud de la formalización de un préstamo mutuo o retribuido.

Sin embargo, pese a que el nominal de la participación preferente no es una deuda del emisor, se insiste en que debe ser calificada como instrumento de deuda subordinada. La participación preferente no es un valor de deuda porque no atribuye a su titular derecho de crédito alguno que le faculte para exigir su pago a la entidad emisora. La disposición adicional segunda de la Ley 13/1985 (núm. 1) obliga a que el dinero captado mediante participaciones preferentes ha de estar invertido en su totalidad (...) y de forma permanente, en la entidad de crédito dominante de la filial emisora, de manera que queden directamente afectos a los riesgos y

11 En Estados Unidos solo pueden emitir acciones preferenciales instituciones financieras o entes públicos; allí no hay exención por dividendos, por lo que el coste de capital financiero-fiscal es hasta un $35 \%$ superior al de las inversiones en deuda a igual tipo de interés. Pese a todo, el tamaño de las emisiones ha alcanzado los 200 millones de dólares a partir de agosto del 2006. En el Reino Unido, las acciones preferentes ordinarias cuentan como capital Tier 1, y si son acumulativas o convertibles, con vencimiento mínimo de cinco años, como capital de nivel 2 (Lower Tier 2 Capital) según las reglas de Basilea. 
situación financiera de dicha entidad de crédito dominante y de la de su grupo o subgrupo consolidable. Por ello, la calificación legal de la participación preferente como instrumento de deuda es incorrecta y también engañosa, aspecto no exento de relevancia ante su colocación entre clientes minoristas ex art. 78 bis LMV.

La participación preferente regulada por la Ley de 1985 se configura así según la naturaleza jurídica propia de una clase especial de acción cuya fuente de regulación es la Ley, al modo como sucede con las acciones sin voto y las acciones rescatables. Mas se trata de una acción desvirtuada y cautiva por cuanto la propia regulación cercena derechos económicos sustanciales propios de la condición de accionista -en concreto, todos los societarios y parte considerable de los patrimoniales-, que resultan en ella excluidos explícitamente. Esta exclusión ha venido a ser confirmada en la referida Directiva 2009/111/CE, del Parlamento Europeo y del Consejo, de 16 de septiembre de 2009, la cual, a diferencia del Derecho español, no califica la participación preferente como instrumento de deuda, sino que, en un ejercicio de indefinición, la califica como instrumento de capital híbrido al que se ha de aplicar el mismo tratamiento contable y financiero que reciben los recursos propios de la entidad de crédito emisora. Esta consideración, a su vez, impide su tratamiento normativo interno como pasivo de la misma, que es lo que sugiere su calificación legal como instrumento de deuda.

La naturaleza accionarial de la participación preferente desde su contenido y función financiera legales deriva de las siguientes razones según la referida disposición adicional segunda de la Ley 13/1985, de 25 de mayo:

(i) La participación preferente es destinataria de un especial régimen o sistema de rentabilidad cuya activación se condiciona legalmente a los resultados económicos de la entidad de crédito emisora (o de los del grupo consolidable en el que ésta se integre), así como, tras la Ley 6/2011, puede depender de la decisión del órgano de administración de ésta. El nacimiento del derecho del inversor en participaciones preferentes al pago de los rendimientos de su inversión (los intereses impropios devengados por el nominal de éstas) está legalmente condicionado a la previa acreditación por la entidad de crédito emisora del cumplimiento de los requerimientos de recursos propios legalmente exigidos a la misma y a su grupo o subgrupo consolidable, así como a la existencia de beneficios o de reservas repartibles; tras la reforma de la Ley 13/1985 por virtud de la Ley 6/2011, el nacimiento del derecho al pago del rendimiento de la inversión puede llegar a depender de la decisión -discrecional en principio- del consejo de administración u órgano equivalente de la entidad de crédito emisora.

(ii) La participación preferente no atribuye derecho a la recuperación de la inversión. A diferencia de lo que acontece en la emisión de valores de renta fija ordinarios, el inversor no puede exigir la restitución de su valor nominal. La 
razón es simple: la preferente es un valor negociado diseñado, como la acción, para su permanencia en el patrimonio del inversor con carácter indefinido. Se trata de un activo potencialmente perpetuo o sin vencimiento, según cuya regulación imperativa el dinero correlativo o correspectivo del título que ha sido captado por la entidad de crédito mediante la aceptación de la oferta de emisión, debe permanecer en la entidad dominante si emite un banco filial, quedando afecto a los riesgos intragrupo, además de soportar los específicos de la entidad dominada. Así, y diferencia de lo que acontece al inversor cuando contrae otras posiciones jurídicas en el mercado, como las de depositante de dinero o de obligacionista ordinario, la correspondiente a adquirir participación preferente no le atribuye derecho de crédito contra la entidad de crédito emisora contra el nominal invertido. Existe riesgo de principal, y este es muy alto en la medida en que el comercializador no detalle al cliente (no lo hace en la práctica, desde luego) la probabilidad de concurso, la distancia a la insolvencia o los riesgos crediticios reales de la entidad.

(iii) Congruentemente con el régimen señalado, la liquidez de la participación preferente solo puede darse en el mercado secundario mediante su venta o enajenación en un espacio de negociación o mercado o plataforma de valores análoga -sistema multilateral de negociación, en el argot post MiFID- en el que ésta cotice regularmente.

(iv) La circunstancia de que el medio exclusivo de recuperación del nominal de la participación preferente sea su venta en un mercado secundario de valores -limitación sustancial de liquidez interna, y remisión exclusiva a los mecanismos de liquidez de mercado- determina que el dinero invertido en ella deviene prácticamente irrecuperable ante los hechos que, legalmente, determinan la desactivación de su sistema de rentabilidad: (i') Que el pago de la misma acarrease que la entidad de crédito dejase de cumplir sus obligaciones en materia de recursos propios o porque no haya obtenido beneficios ni disponga de reservas repartibles; o (ii'), tras la Ley 6/2011, porque así lo decida el órgano de administración de la entidad de crédito. La desactivación del sistema de rentabilidad de la participación preferente y el consiguiente impago de la misma es signo de crisis de la entidad de crédito «deudora» cuyo efecto correlativo en los per se miedosos mercados de valores, es la desaparición de la liquidez de la inversión y la pérdida de su seguridad o posibilidad real de recuperar el dinero invertido. En otros términos: el único incentivo del mercado secundario de participaciones preferentes consiste en el pago regular de sus intereses o sistema de rentabilidad; por tanto, su desactivación elimina la rentabilidad y la liquidez de la inversión así como su seguridad. La participación preferente deja de ser un valor para convertirse en instrumento de inversión de máximo riesgo carente de liquidez, rentabilidad y seguridad. 
(v) El nivel de seguridad en la recuperación de la inversión que ofrece la participación preferente es equiparable al que deparan las acciones. Al igual que sucede con éstas, el único supuesto en el que podría nacer un derecho al pago del valor nominal de la participación preferente sería el de la liquidación de la entidad de crédito emisora (y también de la sociedad dominante de ésta). Pero se establece que el orden de prelación del crédito que en tal caso la participación preferente llegase a atribuir se sitúa legalmente detrás de todos los acreedores, subordinados o no, de la entidad de crédito emisora o de la entidad dominante del grupo o subgrupo consolidable de entidades de crédito en la que ésta se integre. Esto significa que en caso de liquidación de la entidad de crédito emisora (o de su sociedad dominante) la recuperación del dinero invertido en participaciones preferentes exige el previo y completo pago de la totalidad de los créditos de los acreedores de ésta y, acaso, también de los del grupo en el que la misma se integra. Ello revela que la participación preferente es un valor de riesgo equiparable a las acciones o, en su caso, al de las cuotas participativas de cajas de ahorros o de las aportaciones de los socios de las cooperativas de crédito; desde otra perspectiva, cabe afirmar que se trata de acciones con derecho preferente, de fuente legal, al pago de la cuota de liquidación que, en su caso, les pudiera corresponder. Así lo reafirma su regulación legal que, tras su reforma por virtud de la Ley 6/2011, de 11 de abril, exige que las condiciones de emisión de participaciones preferentes fijen un mecanismo que asegure que los inversores tenedores absorban parte de las pérdidas actuales o futuroas del emisor, incluso mediante reducción del nominal de la preferente.

Por tanto, el riesgo que asume el inversor en participaciones preferentes es el mismo que el de los accionistas. Pero con la siguiente particularidad no exenta de interés: los accionistas son titulares de derechos de control sobre el riesgo que soportan, derechos de los que carece el inversor en participaciones preferentes, ya que a éste no se le reconoce derecho alguno de participación en los órganos sociales de la entidad de crédito emisora. Conviene también observar que los accionistas participan de forma directa en la revalorización del patrimonio social del emisor en proporción al valor nominal de sus acciones; en cambio, ante tal eventualidad favorable, el valor nominal de la participación preferente permanece inalterable mientras que, por el contrario, sí cabe su reducción en caso de pérdidas del emisor. Éste es un aspecto especialmente perverso de la participación preferente que por sí solo confirmaría su inaptitud jurídica -e incapacidad económica e ineficienciacomo instrumento de inversión para su compra por clientes minoristas. 


\section{JUSTIFICACIÓN NORMATIVA Y CRÍTICA ÉTICA DEL RÉGIMEN COMUNITARIO Y NACIONAL DE LAS PARTICIPACIONES PREFERENTES HASTA 2012.}

La consideración de la participación preferente desde los intereses típicos inherentes a todo acto de inversión -que éste reporte razonables niveles de seguridad, rentabilidad y liquidez- revela que puede que se trate del peor de los valores negociables regulados en el panorama español. Especialmente si se considera que:

(i) Su régimen o sistema de rentabilidad no es el de una deuda en sentido propio porque su devengo está legalmente supeditado a los resultados del emisor e, incluso, su pago puede depender de la decisión del órgano de administración de éste.

(ii) Su liquidez queda eliminada ipso facto ante situaciones que determinen la desactivación de su sistema de rentabilidad.

(iii) Su seguridad (como posibilidad real de recuperación de la inversión) depende de su nivel de liquidez bajo condiciones de normalidad y regularidad en el pago de su sistema de rentabilidad; o, en su caso, de la existencia de remanente patrimonial suficiente para atender su pago una vez pagados la totalidad de los créditos de los acreedores del emisor y de su grupo empresarial tras la liquidación de éste.

Cabe así concluir que el nivel de riesgo de la inversión en participaciones preferentes es mayor que el deparado por las acciones ordinarias, si se aceptan las acciones como arquetipo del valor de riesgo social o en renta variable. Mayor porque, a diferencia de las acciones ordinarias, la participación preferente es un valor de capital cautivo al estar legalmente desprovisto de cualquier derecho de participación en los órganos sociales de la entidad emisora que permitiese a su titular participar en el control del riesgo asumido; también carece ex lege de derecho de suscripción preferente respecto de futuras emisiones tanto de acciones como de nuevas participaciones preferentes, por lo que no genera rendimientos en forma de venta de derechos de suscripción; la participación preferente tampoco confiere derecho de participación en las ganancias repartibles del emisor ni participa de la revalorización del patrimonio de éste, aunque sí participa en sus pérdidas. Puede darse la paradoja de que el inversor en participaciones preferentes, habiendo asumido un riesgo equiparable al de los accionistas de la entidad de crédito emisora, tenga menor derecho de participación en el beneficio repartido a éstos, ya que lo más habitual es que el rendimiento reportado por la participación preferente consista en la modalidad de «interés» fijo pero devengable bajo las condiciones expuestas. Tras la Ley 6/2011, puede incluso producirse la situación de que los accionistas de la entidad de crédito emisora tuvieren derecho al pago de divi- 
dendo mientras que los titulares de participaciones preferentes no recibieran su rendimiento o interés en función de una decisión del órgano de administración.

\section{LAS NUEVAS (Y LIMITADAS) GARANTÍAS DE INTERVENCIÓN ADMINISTRATIVA, DESDE LA ÓPTICA DEL INVERSOR.}

En el contexto normativo referido, la preferente constituye una especie de acción desnaturalizada, desde los prismas subjetivo (reserva bancaria) y objetivo (de facto es una acción sin voto, sin contraprestación política, con reembolso limitado y sin derecho de suscripción preferente). La participación preferente solo incorpora, como se ha visto, un derecho a dividendo condicionado a los presupuestos ya expuestos. Condicionamiento que privilegia a las entidades emisoras sin contraprestación, pues de hecho pueden emitir acciones con dividendos tasados entre un máximo y un mínimo, en un sistema delimitador que los aproxima de hecho a intereses condicionados, contra la prohibición del art. 96.1 LSC; y además con el agravante, como se ha dicho, de que el banco emisor no solo puede alterar la proporción entre valor nominal y derecho de suscripción preferente (contra 96.3 LSC), sino que se elimina este derecho, con independencia de la confluencia o no de interés social en su exclusión. Como también se ha advertido, carece el inversor de defensa política alguna en junta (asistencia, representación o voto, a diferencia del accionista sin voto que recupera el voto), y de ahí la alta litigiosidad resultante en nuestro país.

Esta severidad regulatoria, y el trato de disfavor hacia el inversor, ha querido paliarla a posteriori el legislador por la extraña, indirecta y extraordinaria vía de la regulación administrativa de los fondos de reestructuración bancaria, incardinando como problema regulatorio público lo que en realidad es un problema de regulación mixta, también privada, de un instrumento utilizado con un sesgo contrario al interés del inversor, con amparo en un régimen extraordinario que favorece los derechos de los emisores asimétricamente. El Decreto Ley 24/2012, de 31 de agosto de 2012, de restructuración y resolución de entidades de crédito, así, constriñe las emisiones al regular el destino de los híbridos (participaciones preferentes y deuda subordinada) emitidos por las entidades intervenidas por el FROB (Fondo de Reestructuración Ordenada Bancaria), que entiende (acertadamente, aunque pueden quedar entidades con crisis encubiertas cuyas emisiones sigan siendo perjudiciales) el problema de las preferentes como una cuestión de déficit gerencial o de governance.

En este sentido, el art. 42.2 de este RDL reserva al FROB acordar "acciones de gestión de instrumentos híbridos de capital y de deuda subordinada que podrá acordar el FROB" tales como el aplazamiento, la suspensión, la eliminación o modificación de determinados derechos, obligaciones, términos y condiciones de todas o alguna de las emisiones, confiriendo un ius variandi ex post que, en interés 


\section{JAVIER IBÁÑEZ JiMÉNEZ}

del inversor, puede afectar a las condiciones esenciales del contrato (pago de intereses, reembolso del principal, supuestos de incumplimiento, vencimiento, derechos individuales o colectivos de los inversores, el derecho de solicitar la declaración de un incumplimiento, o el derecho a exigir cualquier pago relacionado con los valores), pudiendo imponerse al emisor la obligación de recomprar los valores al precio que fije el FROB, que además podrá diseñar el proceso de recompra fijando límites de mercado y primas o descuentos conformes con la normativa europea de ayudas estatales.

Sin embargo, el equilibrio del mercado alcanzado por esta vía administrativa puede no satisfacer al inversor, en la medida en que:

a) Cabe limitar el reembolso al obtenible en caso de liquidación concursal, que puede resultar insuficiente; por tanto, los bancos siguen pudiendo ampararse en el régimen de emisiones vigente.

b) Si el FROB (que puede intervenir en los órganos del emisor en las condiciones dispuestas en el art. $61 \mathrm{RDL}$ ) ordena invertir el precio de recompra en acciones, cuotas participativas o aportaciones al capital social, se fortalece la solvencia del banco para el futuro, pero sin incrementar las probabilidades de recuperación de un justiprecio por el inversor.

c) Si el FROB dispone el pago en especie mediante la entrega de acciones o cuotas participativas disponibles en autocartera directa o indirecta de la entidad, tampoco se garantiza la recuperación del valor invertido, y además se incurre en riesgos no deseados por quien inicialmente era impositor o cuentacorrientista; si bien las condiciones del mercado secundario determinarán la bondad de la solución prevista. ${ }^{12}$

\section{ELRÉGIMENADMINISTRATIVODELALLAMADA“COMPLEJIDAD DE VALORES” Y SU APLICACIÓN AL CASO DEL INVERSOR EN PREFERENTES.}

12 Conforme a lo dispuesto en el art. 61. $3 \mathrm{RDL}$, si la junta o asamblea del emisor obstaculiza o rechaza "la adopción de los acuerdos necesarios para llevar a efecto las medidas de reestructuración o de resolución, así como en los supuestos en que por razones de extraordinaria urgencia no sea posible cumplir los requisitos exigidos por la normativa vigente para la válida constitución y adopción de acuerdos por la junta o asamblea general”, el FROB asumirá aquellas facultades que legal o estatutariamente pudieran corresponder a la junta o asamblea general de la entidad y que resulten necesarias para el ejercicio de las funciones previstas en este real decreto-ley en relación con la reestructuración y resolución de entidades de crédito". Por lo demás, las decisiones y acuerdos que adopte el FROB ex art. 61 "serán impugnables de acuerdo con las normas y procedimientos previstos para la impugnación de acuerdos de las sociedades de capital que sean contrarios a ley. El plazo para ejercitar la acción de impugnación será de 15 días a contar desde el momento en que el FROB proceda a dar publicidad a las actuaciones de conformidad con el artículo 23 del Real Decreto Ley”. 
El art. 79 bis 8.a) LMV considera valores no complejos, expliciter, a los valores típicamente desprovistos de riesgo y a las acciones cotizadas como valores ordinarios cuyo riesgo sea de general conocimiento, así como a los instrumentos del mercado monetario; a las obligaciones u otras formas de deuda titulizada (salvo que incorporen un derivado implícito) y a las participaciones en instituciones de inversión colectiva.

Tampoco reputa complejos a los valores en cuya configuración de mercado concurran las siguientes tres condiciones: (i) Que existan posibilidades frecuentes de venta, reembolso u otro tipo de liquidación de dicho instrumento financiero a precios públicamente disponibles para los miembros en el mercado y que sean precios de mercado o precios ofrecidos, o validados, por sistemas de evaluación independientes del emisor; (ii) que no impliquen pérdidas reales o potenciales para el cliente que excedan del coste de adquisición del instrumento; (iii) que exista a disposición del público información suficiente sobre sus características. Esta información deberá ser comprensible de modo que permita a un cliente minorista medio emitir un juicio fundado para decidir si realiza una operación en ese instrumento.

Considerado este régimen, no puede dudarse que la participación preferente es calificable como valor complejo; no aparece listado como no complejo, ni cumple los tres referidos requisitos. Por tanto, sus comercializadores deben cumplir lo dispuesto en el art. 79 bis. 6 y 7 LMV, si asesoran o de prestan servicios relativos a su distribución a clientes minoristas ${ }^{13}$, lo que deben entenderse en principio al tratarse de un producto complejo. En efecto, la empresa de servicios de inversión -entre las que se incluyen las entidades de crédito- que asesore, coloque, comercialice o preste cualquier clase de servicio de inversión sobre tales valores complejos debe:

a) Obtener información necesaria sobre los conocimientos y experiencia del cliente, incluidos en su caso los clientes potenciales, en el ámbito de inversión correspondiente al tipo de producto o de servicio concreto de que se trate, sobre la situación financiera y los objetivos de inversión de aquél, con la finalidad de poder recomendarle los servicios de inversión e instrumentos financieros que más le convengan. Dicho en el argot, debe realizar un test de idoneidad.

b) Abstenerse de recomendar servicios de inversión o instrumentos financieros al cliente o posible cliente minorista cuando la entidad no obtenga la referida información. Deber abstentivo que revela la imposibilidad de

${ }^{13}$ Modificados por disposición final 3a .5 y 6 de la Ley 9/2012, de 14 de noviembre. Como denuncia Zunzunegui ("Comercialización de participaciones preferentes entre clientela minorista", Revista de Derecho Bancario y Bursátil núm. 130, abril-junio 2013, 252), la reforma es de alcance limitado, y obliga al banco a incluir en la antefirma de la orden compradora la expresión escrita de inconveniencia de la inversión, si el test hecho por el banco muestra que la adquisición del producto es inidónea. 


\section{JAVIER IBÁŃEZ JiMÉNEZ}

vender el producto sin cerciorarse de la idoneidad del comprador, como es propio de prácticas bancarias legales y transparentes, y correlato del deber de prevenir conflictos de interés entre cliente mandante y banco vendedor y comisionista que ofrece el producto a la vez que recoge la orden compradora del cliente ${ }^{14}$.

c) Solicitar al cliente minorista información sobre sus conocimientos y experiencia en el ámbito de inversión correspondiente a la variante concreta de producto o servicio ofrecido o solicitado, con la finalidad de que la entidad pueda evaluar si el servicio o producto de inversión es adecuado para el cliente.

d) Advertir al cliente que el instrumento financiero no es adecuado para él si, sobre la base de esa información, la entidad así lo considera. Si el cliente no proporciona la información requerida o ésta es insuficiente, la entidad tiene el deber de advertirle de que ello le impide determinar si el servicio de inversión o producto previsto es adecuado para él.

La inobservancia de estas obligaciones por la entidad de crédito colocadora de participaciones preferentes entre clientes minoristas puede constituir infracción muy grave o grave según que la inversión realizada por tal cliente le procure o no perjuicios -99.z) bis y 100.t) LMV- además de contribuir a justificar la nulidad del contrato de suscripción de las mismas por parte de clientes minoristas o, en su caso, la responsabilidad contractual de aquélla por los daños derivados para el inversor en ellas.

Ahora bien: procesalmente, la situación del inversor es complicada si se ha interpuesto recurso contencioso administrativo ex art. artículo $70 \mathrm{RDL}$, pues el Juez de lo Mercantil ante el que se ha denunciado al emisor deberá suspender el procedimiento hasta la resolución del recurso contencioso; por lo demás, el art. 72 RDL regula la posibilidad de que el Banco de España o el FROB aleguen ante el juez causas que determinen la imposibilidad material de ejecutar una sentencia que declare antijurídicas decisiones o actos ex 70 y 71 (el recurso contenciosoadministrativo interpuesto). Estas circunstancias dilatan los procedimientos y desamparan al minorista inversor en productos complejos, situación que puede agravarse especialmente si el FROB decide que no se paguen los intereses pactados, sin perjuicio de que pueda decretarse la nulidad o la anulabilidad de la suscripción de participaciones preferentes.

\footnotetext{
${ }^{14}$ Sobre esta problemática, v. nuestro trabajo "Banking Professional Conflicts of Interest in European Securities Markets", Journal of International Banking Law and Regulation, vol. 24, issue 9, septiembre 2009, Sweet \& Maxwell, London, 443-453; y también Ibáñez, J. / Namey, E.: "Nota pluridisciplinar sobre los conflictos de intereses en banca de inversión", Revista Electrónica de Pensamiento Economía y Sociedad, vol. 4, junio 2010, 42-67.
} 


\section{OCULTACIÓN DEL RIESGO INHERENTE A LA NEGOCIACIÓN DE PARTICIPACIONES PREFERENTES E INDUCCIÓN A LA CONTRATACIÓN: RAZONES Y PROBLEMAS.}

\subsection{Razón primera: necesidad de sostener el mercado de ofertas públicas iniciales de venta -IPOs- ante las dificultades de financiación de los bancos y cajas.}

Las entidades de crédito han colocado la mayoría de sus participaciones preferentes entre sus clientes minoristas (cfr. art. 78 bis 4 LMV). A los tales se les ha de presumir su dificultad para comprender la complejidad y el frustrante contenido obligacional de las mismas, máxime si se considera que su suscripción o adquisición les ha sido ofrecida bajo la cuestionable denominación legal de «participación preferente». La técnica de colocación empleada -contacto personal y directo con el cliente a través de la relación de confianza entre éste y el personal de la entidad emisora- puede permitir afirmar que los inversores pueden creer que colocan su ahorro en régimen similar a un depósito de dinero con garantía incluso reforzada (porque son "preferentes») quizás en función de una información insuficiente, acaso tendenciosa, pero no compatible con el régimen de las obligaciones de información ex art. 79 bis LMV respecto de la comercialización de valores complejos y sin, al parecer, haberse respetado las normas en materia de conflicto de intereses aplicables.

Esta situación, aunque rechazable, no deja de ser lógica. Puede afirmarse sin excesivo riesgo de errar que un inversor informado del contenido que subyace bajo la denominación «participación preferente» no invertiría su dinero en ella. Si el inversor minorista es más proclive al riesgo se decantaría por invertir su dinero en acciones de una sociedad cotizada que se distinga por practicar una política de reparto anual de dividendos en cuantía y condiciones de pago aceptables antes que invertirlo en participaciones preferentes. El inversor en acciones cotizadas, comparado con el titular de participaciones preferentes, goza de mayor liquidez para su inversión, tiene probabilidad de revalorización del valor bursátil de su inversión y, seguramente, obtendrá unos rendimientos iguales o mejores que los fijos (o variables) procurados por las participaciones preferentes, ya que el devengo de éstos también depende -al igual que el dividendo- de la existencia de beneficios o de reservas distribuibles por parte del emisor-deudor en cuantía suficiente. Cabe añadir que el gestor profesional de un sistema de inversión institucional (fondo de inversión, fondo de pensiones, etc.) podría no estar exento de culpa (en grado profesional o cualificado) y podría incurrir en consiguiente responsabilidad civil ante los partícipes del sistema en el caso de producirse pérdidas de capital o de rentabilidad derivadas de una inversión en participaciones preferentes fallidas. 


\subsection{Segunda razón: la recurrencia y prevalencia de los conflictos de intereses no debidamente resueltos en banca de inversión.}

Sabido es que los agentes del mercado de valores suelen padecer situaciones de conflicto de interés contractual (son agentes o comisionistas del emisor) y extracontractual (han de dar información relevante, completa y veraz al mercado o a clientes particulares). Así, un gestor de carteras o una empresa de asesoramiento financiero deben reflexionar, y en su caso, apartarse del servicio, antes de recomendar a su clientela la inversión en preferentes. Si se trata de un valor negociable no apto para su colocación entre clientes profesionales ex art. 78 bis 2 y 3 LMV ni entre inversores cualificados (cfr. art. 39 RD 1310/2005) y cuya suscripción o adquisición por inversores institucionales no es aconsejable, resulta que el ámbito para la colocación de participaciones preferentes es, precisamente, el del inversor no informado, normalmente renuente a asumir riesgos de crédito o de precio. Pero precisamente es este el tipo de inversor que, en condiciones normales, confía en el asesoramiento que le presta la entidad de crédito de la que es cliente y al tiempo emisora de sus propias participaciones preferentes. En este orden, el sistema público establecido para proteger la inversión y el ahorro de los inversores ordinarios ha sido puesto a prueba y cabe afirmar que la misma no ha sido superada.

No es fácil de entender la permisividad histórica de los responsables del Banco de España ante la comercialización masiva y directa a minoristas por las entidades de crédito de sus participaciones preferentes durante estos años. Menos cuando las propias entidades han llegado a exhibir como argumento promocional en sus ofertas el nihil obstat de la CNMV y la completitud informativa del folleto de emisión ex art. 30 bis LMV y RD 1310/2005. Si bien la aprobación y registro del folleto de la emisión de valores por la CNMV no supone recomendación alguna de la bondad de tales valores ni garantía del éxito de la inversión, está prohibido que los bancos o cajas induzcan a pensar en cualquier apoyo o respaldo público. Por tanto, si un director de banco o vendedor de preferentes «informa» de que las mismas están «aprobadas y registradas» por la CNMV y el BE, el inversor medio pensará que el Estado avala de algún modo la emisión al aprobarla. De ahí que la responsabilidad de los poderes públicos en la configuración de la ética del mercado no sea un asunto menor ni baladí en estos supuestos.

También las Administraciones están en posición de conflicto de interés en la medida en que deban abstenerse de respaldar la emisión si no tienen una mínima seguridad de que el riesgo asumido por el minorista no es desproporcionado. De ahí que la CNMV use recientemente un sistema de disclaimers ad hoc, que trata de paliar estos fallos de mercado o externalidades adversas para el inversor inducidas por una aprobación y el registro del folleto. 


\subsection{Problema primero. De la clasificación legal de inversores se desprende inequívocamente la condición de minoristas o no inversores no cualificados de los compradores de preferentes, y la insuficiencia de la información servida por el comercializador en la oferta pública.}

Los arts. 38 y 39 RD 1310/2005 contienen la distinción entre tres clases de inversores en valores negociables (u otros instrumentos financieros) con arreglo a diversos criterios como los relativos a su grado de conocimiento o experiencia, sus condiciones subjetivas o su propia elección: (i) El inversor o cliente minorista; (ii) el inversor iniciado o experto; y (iii) el inversor cualificado.

a) Inversor iniciado o experto (art. 38) es aquel en el que, por virtud de sus propias condiciones o porque es asistido por profesionales civilmente responsables ante él en sus decisiones de inversión, se cumplen los fines del folleto informativo de emisión de valores negociables según la funcionalidad de éste ex art. 27.1 LMV: «El folleto contendrá la información relativa al emisor y a los valores que vayan a ser admitidos a negociación en un mercado secundario oficial. El folleto contendrá toda la información que, según la naturaleza específica del emisor y de los valores, sea necesaria para que los inversores puedan hacer una evaluación, con la suficiente información, de los activos y pasivos, de la situación financiera, beneficios y pérdidas, así como de las perspectivas del emisor, y eventualmente del garante, y de los derechos inherentes a tales valores». En esta clase de inversores se incluyen, per se, los inversores cualificados ex art. 39. El resto se delimita en función de criterios cuantitativos (volumen de inversión en una misma clase de valor negociable) o circunstanciales (como las emisiones a demanda y a la medida de un grupo de inversores).

b) Inversor cualificado [art. 30 bis 1.a) LMV y art. 39 RD 1310/2005] es aquel del que cabe presumir un conocimiento notable del funcionamiento de los mercados de valores y de los valores e instrumentos financieros que se comercializan en ellos. Por ello, éste no precisa información alguna para adoptar decisiones de inversión. Se presume que sus propios conocimientos y los que obtiene mediante su infraestructura le son suficientes y pueden suplir la información ex art. 27.1 LMV. Por tanto, al inversor cualificado le es oponible, de iure, la información reglada establecida ante la formulación de ofertas de suscripción de valores negociables u otros instrumentos financieros, información que en algunos casos puede no ser obligatoria.

c) El inversor ordinario o minorista es caracterizado por defecto en el régimen del mercado primario de valores. Es tal, por exclusión, todo inversor que no sea experto o cualificado. Esta clase de inversor minorista es indicativa de la existencia de una laguna en el sistema protector de la inversión en el ámbito del mercado primario. Es indicativa de que hay una clase inversor que a pesar de disponer de la información legal reglada y, en su caso, obligatoria, no puede estar en condiciones 


\section{JAVIER IBÁÑEZ JiMÉNEZ}

de hacer la evaluación que la misma le debería poder procurar sobre el emisor y sobre el contenido obligacional que incorporan los valores o instrumentos financieros cuya suscripción les sea ofrecida. La información legal preceptiva resulta inocua respecto de esta clase de inversor y puede que hasta contraproducente. La información realmente relevante ante este tipo de inversor es la que proviene de la confianza que le inspira la relación de clientela que mantiene con el comercializador de los valores, máxime si éste es una entidad de crédito.

Este inversor minorista es merecedor de mejor protección jurídica que la procurada por la autotutela del inversor previo acceso a una información reglada sobre el emisor y los valores que rige el mercado primario. Este régimen beneficia mayormente al emisor y a quienes comercializan los valores entre tal clase de inversores ya que la información registrada y aprobada por la CNMV tiende a actuar como excepción oponible ante ellos si la inversión les produce perjuicios o resulta fallida. Que el emisor informe en folleto cumpliendo sus obligaciones legales de información suele invocarse judicialmente como eximente de responsabilidad ante el inversor minorista; el problema es que la información legal es insuficiente; además, la función de la información del mercado primario no es eximir de responsabilidad civil al emisor, director y colocadores de los valores, sino la de procurar que los potenciales inversores dispongan de datos para evaluar correctamente el nivel de seguridad jurídica, rentabilidad económica y liquidez y demás riesgos asociados a la inversión que se les propone en la oferta inicial primaria o initial public offer-IPO; cf. 25 a 30 LMV-. Si el minorista, leído el folleto, o el contrato celebrado con el banco, sigue sin informarse debidamente, el cumplimiento de las normas vigentes sobre transparencia no ampara la posición de emisores, comercializadores y demás sujetos intervinientes; lo contrario contradiría las exigencias de la buena fe, y el espíritu y finalidad de las reglas jurídicas aplicables ( $c f .3,6$ y 7 CC; 1 y 78 LMV).

Por ello, se ha de afirmar cabalmente el nacimiento de obligaciones contractuales, celebrada una IPO, que vinculan al emisor generando responsabilidad de la persona jurídica emisora y de los demás sujetos intervinientes en los procesos de colocación de los valores ofertados, allende y al margen de cuáles sean los medios de defensa o de tutela dispuestos por el ordenamiento en normas concretas de responsabilidad. La IPO se acepta generando un negocio jurídico cuyo consentimiento viene basado en el tratamiento inadecuado de una información insuficiente, que no puede ser calificada como completa, y que no es operativa o funcionalmente capaz de generar un consentimiento válido, merced a la ineficiencia de la Ley y de un proceso eventualmente torcido de colocación, aseguramiento y suscripción o aceptación de la IPO cuando tiene lugar por redes de información bancaria entre inversores minoristas, máxime si tal colocación es efectuada a iniciativa del propio emisor y mediante trato personal y directo con clientes antiguos o consolidados. 
7.4. Problema segundo: la transposición ya próxima a la crisis de la Directiva 2004/39/CE (MIFID) por Ley 47/2007, de 19 de diciembre, que reforma la LMV ad hoc, y por Decreto 217/2008, de 15 de febrero.

La Directiva de mercados (MiFID) confirma en su articulado la insuficiencia de la información reglada como sistema tutelar del inversor minorista; de ahí su empeño en comprometer a los prestadores de servicios de inversión, y especialmente a los bancos cuando operan en el mercado de valores ${ }^{15}$. Ante el cliente minorista (por defecto, el no profesional o que no sea contraparte elegible ex art. 78 bis y ter LMV), la información reglada sobre instrumentos financieros es ineficiente. Es preciso establecer obligaciones de diligencia profesional de imperativo seguimiento ante él por parte de la entidad a través de la cual aquél canaliza sus decisiones de inversión en valores negociables y cuyo incumplimiento sea fuente de responsabilidad contractual de la misma y, caso de que tal entidad sea al tiempo emisora de los valores, la consecuencia de la infracción no debe detenerse en la responsabilidad contractual referida, sino que debe poder fundar ex post la invalidez de los contratos de suscripción.

7.5. Problema tercero: como sustrato del problema jurídico subyace el dilema ético interno de los prestadores de servicios de inversión, participaciones preferentes y obligaciones de la entidad prestadora de servicios de inversión a clientes minoristas.

Tal dilema se produce en el seno de la voluntad de quienes reciben el encargo, generalmente bajo promesa de comisiones o premios retributivos (o simplemente en el marco de una relación laboral) de colocar participaciones preferentes entre clientes minoristas.

En este ámbito, las entidades de crédito contraen siempre el deber general de comportarse "con diligencia y transparencia en interés de sus clientes, cuidando de tales intereses" quam in suis, y, en particular, observando las normas establecidas en los art. 79 ss. LMV, de suerte que la entidad informe siempre adecuadamente a sus clientes de manera "imparcial, clara y no engañosa" a fin de que conozca "la naturaleza y los riesgos del tipo específico de instrumento financiero que se ofrece pudiendo, por tanto, tomar deci-

${ }^{15}$ Cf. Ibáñez, J. / Namey, E. (2010): "Nota pluridisciplinar sobre los conflictos de intereses en banca de inversión", 4 Revista Electrónica de Pensamiento Econonomía y Sociedad, 42-67; ÍD. (2011), "Gobierno de los bancos y conflictos de interés con clientes: neoliberalismo vs RSE", 3 (1) Revista de Responsabilidad Social de la Empresa. Fundación Luis Vives, 105-129; ÍD., "Grabbing v Helping-Banking Supervision Dilemma: A Global Approach to Enhanced Banking-Law Compliance" (2011), 26 (3), Journal of International Banking Law and Regulation, 123-131. 
siones sobre las inversiones con conocimiento de causa" $-c f$. arts. 1, 60 y ss. RD 217/2008, de 15 de febrero, que desarrolla estos preceptos de la LMV_ ${ }^{16}$.

\subsection{Participaciones preferentes y conflicto de intereses entre la entidad pres- tadora de servicios de inversión y sus clientes.}

El art. 70 quáter LMV regula las bases del tratamiento del conflicto de intereses entre las empresas prestadoras de servicios de inversión y sus clientes, sean o no minoristas. Existe conflicto de intereses cuando la empresa prestadora del servicio pueda obtener un beneficio correlativo a un posible perjuicio para un cliente; o cuando un cliente puede obtener una ganancia o evitar una pérdida con posibilidad de pérdida concomitante del cliente. La empresa prestadora de servicios de inversión tiene la obligación legal de aprobar, aplicar y mantener una política de gestión de los conflictos de interés eficaz y apropiada a su organización, destinada a impedir que tales

${ }^{16} \mathrm{El}$ asesor de inversión o gestor de carteras debe recabar del minorista "la información necesaria" para aconsejarle de modo que decida racionalmente; y el comisionista o bróker de valores complejos, con o sin prestación de servicios auxiliares, debe pedir al cliente información sobre sus conocimientos y experiencia en el ámbito de inversión correspondiente al tipo concreto de producto o servicio ofrecido o solicitado, también con la finalidad de evaluar si el servicio o producto de inversión es adecuado. $\mathrm{Si}$, en base a esa información, la entidad considera que el producto o el servicio de inversión no lo es, ha de advertirle al respecto. Si el cliente no proporciona la información indicada o ésta sea insuficiente, la entidad debe advertirle de que ello le impide determinar si el servicio de inversión o producto previsto es adecuado para él ( 79 bis 7 y 8 LMV). Los defectos en el cumplimiento de sus obligaciones de información por la entidad de crédito prestadora de los referidos servicios de inversión relativos a participaciones preferentes, sobre todo en el aspecto relativo al carácter imparcial de tal información, y de advertencia sobre la inadecuación del valor al perfil del inversor (y, acaso, por las infracciones en materia de prevención de las situaciones de conflicto de intereses a las que ahora se alude) podría indicar la concurrencia de defecto del consentimiento de los suscriptores que tuvieren la condición legal de clientes minoristas, tara invalidante del mismo en función de la eventual concurrencia de culpa en los tratos preliminares de la entidad de crédito emisora y colocadora según las tales premisas, o bien de un error obstativo para la libre prestación del consentimiento del inversor ante la contratación de tal valor complejo (1266 CC), cuya estimación determinaría la aplicación del art. 1303 CC -que exige la restitución recíproca del objeto y el precio contratado, con intereses-. En este orden sería procedente la aplicación del régimen de integración en los contratos de suscripción de tales valores de la publicidad real sobre los mismos realizadas por los colocadores en la promoción directa de su colocación ante sus clientes si se prueba que en la misma se han minimizado o excluido los riesgos del valor cuya suscripción se oferta y se han maximizado las ventajas esperables del mismo por encima de la información reglada propia de los folletos e, incluso, de la derivada de la legislación del valor (como es el caso de las participaciones preferentes al ser éstas un valor regulado. Para una idea sobre la evolución jurisprudencial en torno a estas consideraciones, v. sentencias de la Sección $1^{\text {a }}$ AP Valladolid, 20/02/2012 (EDJ 2012/24115); Sección 10 ${ }^{a}$ AP Madrid, 26/06/2012 (EDJ 2012/161367); Sección 19a AP Madrid, 15/03/2012 (EDJ 2012/178968); Sección 5a AP Murcia, 01/04/2011 (EDJ 2011/82069); Sección $5^{\mathrm{a}}$ AP Baleares, 02/09/2011 (EDJ 2011/216194) y Sección 2a AP Zaragoza, 17/04/2012 (ROJ SAP Z 952/2012). Pueden consultarse más referencias en Guerrero (2012), "Las acciones y participaciones preferentes. acciones judiciales y estrategias de defensa", Revista Aranzadi Doctrinal 6/2012, BIB 2012 22850; PÉREZ DAUDÍ / SÁNCHEZ GARCÍA, "Las participaciones preferentes de entidades financieras intervenidas. Análisis de las posibilidades procesales del inversor", El Derecho, Tribuna, 26.09.2012, passim, acceso 11.10.2012,http://www.elderecho.com/www-elderechocom/participaciones-financieras-intervenidas-Analisis-posibilidades_11_454930003.html 
situaciones perjudiquen los intereses de sus clientes. En caso de insuficiencia de las medidas organizativas dirigidas a garantizar, con razonable certeza, la prevención de los riesgos de perjuicio para los intereses del cliente, la empresa de servicios de inversión debe entonces revelar previamente la naturaleza y origen del conflicto al cliente antes de actuar por cuenta del mismo.

El art. 44 RD 217/2008, de 15 de febrero, establece criterios más concretos ante la identificación de los conflictos de interés potencialmente perjudiciales para los clientes del prestador de servicios de inversión. El criterio mínimo atiende a si la propia empresa prestadora de tales servicios o bien una persona competente u otra persona directa o indirectamente vinculada a aquélla por una relación de control, se encuentra en alguna de las siguientes situaciones: a) La entidad o la persona en cuestión puede obtener un beneficio financiero, o evitar una pérdida financiera, a costa del cliente; b) tiene un interés en el resultado del servicio prestado o de la operación efectuada por cuenta del cliente, distinto del interés del propio cliente en ese resultado; c) tiene incentivos financieros o de cualquier otro tipo para favorecer los intereses de terceros clientes, frente a los propios intereses del cliente en cuestión; d) la actividad profesional es idéntica a la del cliente; e) recibe, o va a recibir, de un tercero un incentivo en relación con el servicio prestado al cliente, en dinero, bienes o servicios, distinto de la comisión o retribución habitual por el servicio en cuestión. Pero se especifica que, en cualquier caso, no se considerará suficiente el que la empresa pueda obtener un beneficio, si no existe también un posible perjuicio para un cliente; o que un cliente pueda obtener una ganancia o evitar una pérdida, si no existe la posibilidad de pérdida concomitante de un cliente. Cabe afirmar entonces que el potencial perjuicio para el cliente es el criterio central para determinar la existencia de una situación de conflicto de intereses entre los de éste y los de la entidad que le presta servicios de inversión.

En la colocación de participaciones preferentes por entidades de crédito entre su clientela minorista existe una situación manifiesta de conflicto de intereses entre aquéllas y éstos en la medida en que concurren los supuestos a) y b) del transcrito art. 44 RD 217/2008. La entidad de crédito emisora puede obtener beneficio, o evitar pérdidas, a costa del cliente. La entidad obtiene un beneficio obvio en la colocación: transforma pasivo en recursos propios y se financia a coste desigual respecto al riesgo transferido. Por esa misma razón, la entidad de crédito tiene un interés directo en el resultado del servicio prestado o de la operación efectuada por cuenta del cliente, distinto del interés del propio cliente en ese resultado.

Viniendo la entidad obligada ex 70 quáter LMV a impedir que los conflictos de interés perjudiquen a clientes, debe responder ex contractu ante su clientela minorista perjudicada por la suscripción de participaciones preferentes si el daño del inversor está ligado a la conculcación del deber de abstención o información en posición de conflicto de interés. Como se ha visto, es inadecuada e inefi- 


\section{JAVIER IBÁŃEZ JiMÉNEZ}

ciente la inversión en preferentes para un minorista adverso al riesgo. Por lo demás, mediando en la praxis información insuficiente o engañosa ex 79 LMV, RD 217/2008 7 de la Ley 3/1991, de 10 de enero, de Competencia Desleal (LCD), se dan comportamientos objetiva (y éticamente) contrarios a las exigencias de la buena fe -4.1 LCD- en el emisor medio, en relación con el adquirente o cliente medio. Obviamente, el sistema distributivo de títulos mermaba "de manera apreciable su capacidad de adoptar una decisión con pleno conocimiento de causa, haciendo así que tome una decisión sobre su comportamiento económico que de otro modo no hubiera tomado" (1269 y 1270 CC, $4.1 .4 .^{\circ}$ LCD).

\section{A MODO DE CIERRE.}

No es razonable que el cliente minorista, modelo de ahorrador básico, opte por sí libremente a asumir posiciones inversoras de máximo nivel de riesgo; menos, en reemplazo de un depósito bancario. Es notorio que tal tipo de cliente ha de ser directa o indirectamente inducido a invertir, y que tal modelo de comportamiento contractual solo se explica por persuasión e inducción vía técnicas de colocación que presuponen intervención en la oferta de manera directa y personal por parte del emisor o sus representantes o agentes, a través de sus propias redes de oficinas.

Es prácticamente impensable que en la transmisión del contenido de la oferta al inversor pueda detectar este información que, aun veraz, por su contenido o presentación le mueva a error ( $c f .7 \mathrm{LCD})$, especialmente habiendo sido tratada la información por el vendedor u oferente de manera no clara, ininteligible, ambigua e intempestiva.

La gravedad de los conflictos de intereses y de las situaciones conflictivas contractuales padecidas por directivos y comercializadores bancarios (vs clientes) y por los prestadores de servicios de inversión (que se deben tanto a sus banqueros emisores como a sus propios clientes) hacen urgente una redefinición de los derechos contractuales en este tipo de emisiones, allende los remedios administrativos excepcionales previstos en el régimen del FROB.

\section{BIBLIOGRAFÍA.}

ALONSO ESPINOSA, F., "Participaciones preferentes y clientes minoristas de entidades de crédito", 7875 Diario la Ley, Sección Doctrina, XXIII, 7.06.2012.

BANCO DE PAGOS INTERNACIONALES (2008), $78^{\circ}$ INFORME ANUAL (1 de abril de 2007-31 de marzo de 2008). 
CATARINEU, E. y PÉREZ, D., "La titulización de activos por parte de las entidades de crédito: El modelo español en el contexto internacional y su tratamiento desde el punto de vista de la regulación prudencial”, Estabilidad Financiera (núm. 14, 2008), pp. 87-121

COMITÉ DE SUPERVISIÓN DE BASILEA, Principios básicos para una supervisión bancaria eficaz, septiembre, 2012, www.bis.org., acceso marzo de 2014.

DODD, R.: "Los tentáculos de la crisis hipotecaria", Finanzas $\mathcal{E}$ desarrollo (diciembre 2007), pp. 15-19.

DREVINEK, K. y SEVERA, P., "Getting the Deal Through: Czech Republic" sub 3, "Rights and Equitable Treatment of Shareholders, en Weil News Publications, 2005, acceso en marzo de 2014 vía http://www.weil.com/news/ pubdetail.aspx?pub=3648

FENDER, I. y MITCHEL, J.: "Structured finance: complexity, risk and the use of rating”, Bank of International Settlements Quarterly Review ( junio 2005), pp. 67-79.

FERNÁNDEZ DEL POZO, L. Las participaciones preferentes: un híbrido financiero supletorio al capital social, Civitas / Thomson Reuters, Madrid, 1995.

FERNÁNDEZ-ARMESTO, J., "La ética en los mercados de valores, problema crucial de las sociedades y sistemas capitalistas contemporáneos", en Ibáñez, J. y Fernández, J. L. (dirs.), Ética y mercado de valores, Marcial Pons, Madrid, 2002, pp. 17-24.

IBÁÑ̃Z JIMÉNEZ, J., "Ética y normas de conducta profesional en el mercado de valores", en Ibáñez, J. y Fernández, J. L. (dirs), Ética y mercado de valores, Marcial Pons, Madrid, 2002, pp. 44-49.

"Banking Professional Conflicts of Interest in European Securities Markets", Journal of International Banking Law and Regulation (vol. 24, issue 9, septiembre 2009) Sweet \& Maxwell, London, pp. 443-453.

IBÁÑEZ, J. y NAMEY, E.: "Nota pluridisciplinar sobre los conflictos de intereses en banca de inversion, Revista Electrónica de Pensamiento Economía y Sociedad ( vol. 4, junio 2010), pp. 42-67.

PARTAL UREÑA, A. / IBÁÑEZ JIMÉNEZ, J.W. "Desencadenantes de la crisis financiera: la financiación estructurada", 13 Revista Electrónica de Pensamiento, Economía y Sociedad (REPES), 2012, 81-76.

RUIZ MARTÍNEZ, R. / IBÁÑEZ, J., "El inversor como víctima de la publicidad financiera", en IBÁÑEZ, J. / FERNÁNDEZ, J. L. -dirs.- (2002), Ética y mercado de valores, Marcial Pons, 95-102.

SCHWARZ, G. C.: Europäisches Gesellschaftsrecht-ein Handbuch fuer Wissenschaft und Praxis, Baden Baden, 2000.

ZUNZUNEGUI PASTOR, F.: "Comercialización de participaciones preferentes entre clientela minorista", Revista de Derecho Bancario y Bursátil (núm. 130, abril-junio 2013), pp. 239-271. 